\title{
Eating and Drinking in Childhood
}

\author{
Sophie Nicklaus
}

\section{Contents}

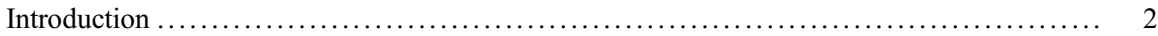

Infancy: Drinking and Eating before the Onset of Food Neophobia: The Golden Age ....... 4

The Preschool Age: A Neophobic Phase, Source of Family Tensions ................... 8

School Age: A Curious, Autonomous Eater Still Framed by Parental Practices ............ 11

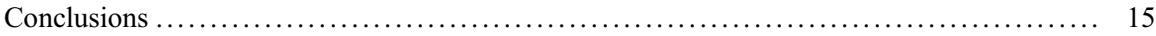

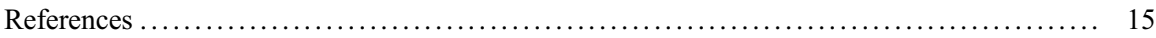

\begin{abstract}
This chapter describes the development of eating and drinking in typically developing children up to the end of school age. Together with physiological and cognitive development, children's eating behavior undergoes major evolutions. During the early period when eating is essential to sustain growth, children eat easily and at the onset of complementary feeding discover the foods of their future diet which are marked by distinct tastes, flavors, and textures from the milk they had received before. Then they undergo a period when they may become picky and/or neophobic, which may last until school age. For this reason, eating and drinking will first be described in infancy, before the onset of food neophobia (from birth to 2-3 years), during the preschool years (from 2-3 years to 6 years), and right after this period, in school-aged children (from 7 years until 11 years). The mysteries of (pre)adolescent eating and drinking will not be covered in this chapter. Then, within each section, the following aspects will be covered: sensory capacities, likes and dislikes, attitudes and thinking, and role of the environment, including the family environment.
\end{abstract}

S. Nicklaus $(\square)$

Centre des Sciences du Goût et de l'Alimentation, AgroSup Dijon, CNRS, INRAE, Université Bourgogne Franche-Comté, Dijon, France

e-mail: sophie.nicklaus@inrae.fr 


\section{Keywords}

Children $\cdot$ Eating $\cdot$ Drinking $\cdot$ Healthy foods $\cdot$ Unhealthy foods $\cdot$ Taste $\cdot$ Smell $\cdot$

Texture $\cdot$ Pleasure $\cdot$ Cognition $\cdot$ Parental feeding practices

\section{Introduction}

How to cover such a complex topic as eating in childhood in one chapter? It is a challenge, because eating and drinking in childhood are nearly as complex as in adulthood, if not more, given the developmental aspect specific to childhood! Infants are born with sucking abilities and within a year from birth will transition from their mother's breast to the family table. What a journey through eating and drinking! First, concerning childhood, it may be relevant to refer to "drinking and eating" rather than to "eating and drinking," because children start their journey through the consumption of foods and drinks by first consuming a unique liquid substance, (breast) milk. It is only by about the first half of the first year that foods other than milk start being consumed. This corresponds to the recommendation of the World Health Organization regarding the ideal age for introduction to complementary foods (WHO World Health Organization 2003). This recommendation is universal because according to the WHO, human milk is the most adapted food for all newborns, but this is all the more true in parts of the world where access to potable water (which is needed for the preparation of infant formula as a substitute for breast milk) is not granted. However, because some women have working activities outside the households in many countries, a transition to other foods than breast milk may be necessary before the age of 6 months, which may have led pediatric societies throughout the world to suggest the introduction to complementary foods as of the age of 4 months (as observed for the European Society for Paediatric Gastroenterology, Hepatology, and Nutrition (Fewtrell et al. 2017), the Chinese Ministry of Health, and the Japanese Ministry of Health (in (Inoue and Binns 2014)), to name a few examples). The WHO recommendation is related to the protective effect of breastfeeding against infections and, as suggested more recently, to the positive (but unwanted) association between the initiation of complementary feeding before 4 months and the development of overweight and obesity (English et al. 2019). Introduction of complementary foods about the first half of the first year is also related to the developing feeding skills of the infant, which strongly evolve during the course of the first year (Fewtrell et al. 2017; Nicklaus et al. 2015). When the oral cavity increases in size, when lips and the tongue are able to retain food in the mouth, when coordinated lateral then rotatory movements of the jaws are developing, only then is the infant able to process foods other than liquids in the mouth (Nicklaus et al. 2015). These tremendous developmental features happen in a relatively short period, which constitute a "window of opportunity" to learn about food (Nicklaus 2016b). Therefore, during childhood, "eating and drinking" first mean drinking and progressively mean eating at the family table where children will ultimately eat like their parents, if they are provided with the opportunity to learn about "adult" foods. 
"Eating and drinking" in childhood must also be considered in relation to the various functions of eating and drinking. In childhood as later during adulthood, "drinking and eating" first serve the primary function of covering nutritional needs for maintaining body functions, with the specific nutritional need to cover healthy growth. Second, "drinking and eating" deliver pleasure, through the presence of the mother (importance of her physical contact as shown in skin-to-skin practice, of her body warmth, of her voice, her smell, etc.) (Schaal 1988), through the positive reinforcement related to the cessation of the painful feelings related to hunger, to the satisfaction related to satiation and the ingestion of calories, and through the pleasurable sensory properties of foods that are either immediately pleasant to the child or learned through experience with foods. Third, "drinking and eating" contribute to socialization; and for children it is essential to learn to eat like their siblings, in order to develop social competencies that will enable their integration to social activities encompassing eating, such as schooling. Finally, because drinking and eating are so embedded into our daily lives, they also contribute to define one's identity, and the food choices that we make daily carry important symbolic values toward others. This is true also in children, and many of children's reactions to parental feeding strategies can also be interpreted in relation to defining their own identity.

In order to describe the main features of eating and drinking in childhood, this chapter is organized in different sections related to the main stages related to eating in this particular age range. One important dimension to account for regarding eating in children is the development of a phase during which children exhibit strong neophobic reactions (i.e., reluctance to eat and try new foods) and may come to reject foods that were previously eaten. This phase generally starts by the end of the second year, when marked signs of food neophobia/fussiness/pickiness become the norm (and may concern at least three children out of four), and fades away by about 8 years of age (Dovey et al. 2008; Nicklaus and Monnery-Patris 2018; Rioux in press; Taylor et al. 2015). For this reason, eating and drinking will first be described in infancy, before the onset of food neophobia (from birth to 2-3 years), during the preschool years (from 2-3 years to 6 years), and right after this period, in schoolaged children (from 7 years until 11 years). The mysteries of (pre)adolescent eating and drinking will not be covered in this chapter. Then, within each section, several aspects related to eating will be described. First, sensory capacities will be exposed, because at an early stage in life, sensory-motor inputs play a particularly important role in determining food choice decision-making. Then, likes and dislikes will be explained, which develop in relation to dietary experience. Third, attitudes and thinking abilities will be described, since cognitive abilities strongly evolve across childhood. Finally the role of the environment in shaping eating and drinking will be explained, focusing in particular on the role of the social environment (including family environment), which changes drastically across development.

This chapter focuses on the development of eating behavior of typically developing children and does not cover the potential specific needs of children with atypical development, whether it stems from physiological or psychological impairment. Furthermore, most of the studies used to document this chapter were conducted in 
Western Europe or in the USA. While one may reasonably assume that these pieces of evidence relate to fundamental learning mechanisms, in relation to physiological and psychosocial factors, it may be questioned whether the phenomena described in this chapter hold true in all parts of the world. More specifically, many factors that strongly relate to the development of eating and drinking are so variable across the globe (food availability (in relation to climate variations), cooking habits, culture and prejudices about infant and child feeding, socioeconomic development, parental feeding practices, parental feeding and parenting style, exposure to food commercial, etc.) that their independent or combined influences on all aspects of children's development of eating and drinking are not known with precision. Whenever possible, examples from non-Western countries will be exposed.

\section{Infancy: Drinking and Eating before the Onset of Food Neophobia: The Golden Age}

Sensory abilities. Infants are born with the capacity to taste and smell drinks and foods (Lipchock et al. 2011). While it is difficult, if not impossible, to compare infants and adults sensitivities to tastes and smells in line with strong differences in applicable methods, several studies indicate that infants display finely tuned abilities to differentiate flavors of foods and drinks, which can be inferred from their preferences. For instance, they can distinguish the smell of milk from that of water, the smell of breast milk from that of formula milk, and the smell of their mother's milk from the smell of another lactating woman (Marlier et al. 1998). They can also demonstrate a preference for an odor that was experienced in utero, which also reveals the transnatal continuity in terms of food flavor learning (Schaal 2005). They can differentiate and prefer the odor of vanilla compared to the odor of butyric acid (Soussignan et al. 1997). Concerning taste perceptions, newborns are able to display a variety of facial expressions and behavioral responses when they are exposed to the different primary tastes (sweet, salty, sour, bitter, and umami) (Lipchock et al. 2011). Later in development during infancy, infants still show contrasted preferences across the primary tastes, but preference for all tastes do not evolve in the same way: for instance, the preference for salty taste increases sharply during the first year (Schwartz et al. 2017). Regarding manipulation of food textures, infants are born with very limited oral skills that only enable sucking during the first months (Nicklaus et al. 2015). However, they can develop control over sucking during the first months and can refrain from drinking a formula milk that they do not like, as was shown in the case of hydrolyzed protein formula (generally prescribed in case of allergy to cow milk proteins). Such formulas have a strong flavor (bitter, sour, in relation to the hydrolysis of the formula into smaller peptides), which children start rejecting around the age of 3.5 months (Trabulsi and Mennella 2012). Their abilities to develop more sophisticated oral control over food gradually evolve during the first years of life, but it is only when final denture is in place that chewing efficiency of children reaches adult maturity (Nicklaus et al. 2015). This happens during preadolescence. 
Food likes and dislikes. In relation with these finely tuned and developing sensory abilities, infants exhibit a marked development in terms of food likes and dislikes. From birth on, their preferences are strongly dependent upon their food and flavor experience (Nicklaus 2016a; Schaal 2016; Trabulsi and Mennella 2012). This may be interpreted as an adaptation mechanism to enable the chemosensory guidance toward foods that are safe to eat within a given environment. This conclusion may appear as very broad, but several pieces of evidence can support it. At birth, preference for an odor can be guided by prenatal exposure to the same odor present in a food consumed by mother: this was shown concerning the consumption of food containing the anise flavor (Schaal et al. 2000). At the start of complementary feeding, children's preference for food flavor can be related to prior learning, during pregnancy as shown regarding exposure to carrot flavor (Mennella et al. 2001) or to green vegetable flavor (Wagner et al. 2019) or to prior learning during lactation as shown regarding exposure to carrot flavor (Mennella et al. 2001), to caraway flavor (Hausner et al. 2010; Wagner et al. 2019), or to green vegetable flavor (Wagner et al. 2019). The exposure to the flavor of garlic during pregnancy was even shown to influence children's preference for garlic flavor in a potato gratin up to adolescence (Hepper et al. 2013). The exposure to vanilla flavor in the context of milk feeding was shown to influence adult's preference for vanilla flavor in a ketchup (Haller et al. 1999), revealing the long-term influence of such an early sensory imprinting on food preference. Epidemiological studies also point to the association between breastfeeding and further acceptance of fruit and vegetables (Burnier et al. 2011; de Lauzon-Guillain et al. 2013; Skinner et al. 2002).

Preferences for foods at the onset of complementary feeding can be modulated by milk feeding experience, in relation to the milk composition independently from the maternal food consumption, in the context of breast milk (Schwartz et al. 2013) or formula feeding (Beauchamp and Mennella 2011). After the initiation of complementary feeding (introduction of foods other than milk to the child's diet), children can process foods which have a soft texture (like infant cereals or purees foods) but are still limited in their ability to process hard/chewy foods (Demonteil et al. 2019), but in terms of flavors, they tend to accept a wide variety of foods (Lange et al. 2013). Notably, the liking of a food (judged from parental reports) can differ as a function of food taste, and infants may like more foods that have a saltier taste (Schwartz et al. 2011), in relation with the development of salt taste preference (Schwartz et al. 2017). This is not a good news because the consumption of sodium is advised against at this stage of life, in relation to kidney immature functioning.

The beginning of complementary feeding itself is fundamental period for children for learning about foods. Many experiments conducted during this period show that repeated exposures help children to like a variety of foods (Sullivan and Birch 1994), even foods they did not like right away (Maier et al. 2007). The diversity or variety of foods fed during this period is also strongly supporting the development of likes for unknown foods. Studies in this area showed that the introduction of three different types of vegetables (or fruits) at the very beginning of complementary feeding instead of one type only is associated with a higher acceptance of a new food right after this period (Gerrish and Mennella 2001; Maier et al. 2008; Mallan et al. 2016; 
Mennella et al. 2008), which demonstrated lasting effects on intake of familiar or novel vegetables up until the age of 6 years (Maier-Nöth et al. 2016). The effect of the introduction of a variety of foods on the development of food preference may depend on the age of children: a study conducted in the UK showed an effect of the introduction to a variety of vegetables on acceptance of a new vegetable in infants introduced to complementary foods after 6 months, but not before 6 months (Coulthard et al. 2014). A study conducted in three cultural contexts (the UK, Greece, and Portugal) where feeding practices are different (high vegetable variety at the beginning of complementary feeding in Portugal but low in Greece and the UK) showed that the effect of an imposed pattern of vegetable variety introduction has more effect on children's acceptance of a new vegetable in countries where parents were not culturally inclined to provide a high variety of vegetables (e.g., in the UK and Greece) than in a country where an introduction of a high variety of vegetables is the norm (e.g., in Portugal) (Fildes et al. 2015).

Having a look about the first complementary foods that are fed around the world is useful to understand how early feeding practices relate to cultural eating habits, as represented in Fig. 1. The types of foods fed in a given culture are generally related to the food availability in this country, to the existence of core foods in the diet (e.g., tortilla in Mexico, legumes and nuts in India, tuber and roots in Egypt). Some regularities can also be observed, like the use of local or commercial cereals or grains and the introduction of vegetal products, like fruit, vegetable, roots, and tuber, while the diet is still rich in milk.

Altogether, this period appears as fundamental for learning about food likes. Beyond the repeated exposure mechanism for learning (or mere exposure), forms of Pavlovian conditioning may also modify children's behavior toward foods (as far as intake or liking are concerned). Preference for an unknown flavor (the conditioned stimulus) may be conditioned by a liked flavor (the unconditioned stimulus, e.g., the sweet taste) in the case of flavor-flavor learning or by the presence of nutrients (the unconditioned stimulus being calories) in the case of flavor-nutrient learning. This has been studied in infants, but the actual contributions of these mechanisms are still controversial (Yeomans 2012). Flavor-flavor learning (with sugar as the unconditioned stimulus) does not produce significant effect on learning to like a new vegetable, but the association of the flavor of a food to calories from lipids may in fact be associated with conditioned satiation (Caton et al. 2014; Remy et al. 2013), revealing the importance of energy density in conditioning food intake. More studies are needed to better understand learning mechanisms for a range of foods with a range of flavor additions, or of energy densities, in order to understand which flavor intensity and which energy density would be associated with the highest increase in liking an intake, especially for foods which are not liked right away by children such as vegetables.

Attitudes and thinking. Although children are mostly in a preverbal stage during this early period before the onset of food neophobia, they start developing representations about foods, either related to whether foods are edible or not (Fallon et al. 1984) or whether foods "smell good or bad" (Wagner et al. 2013). By the beginning of the second year of life, when infants watch people eating different foods, they 


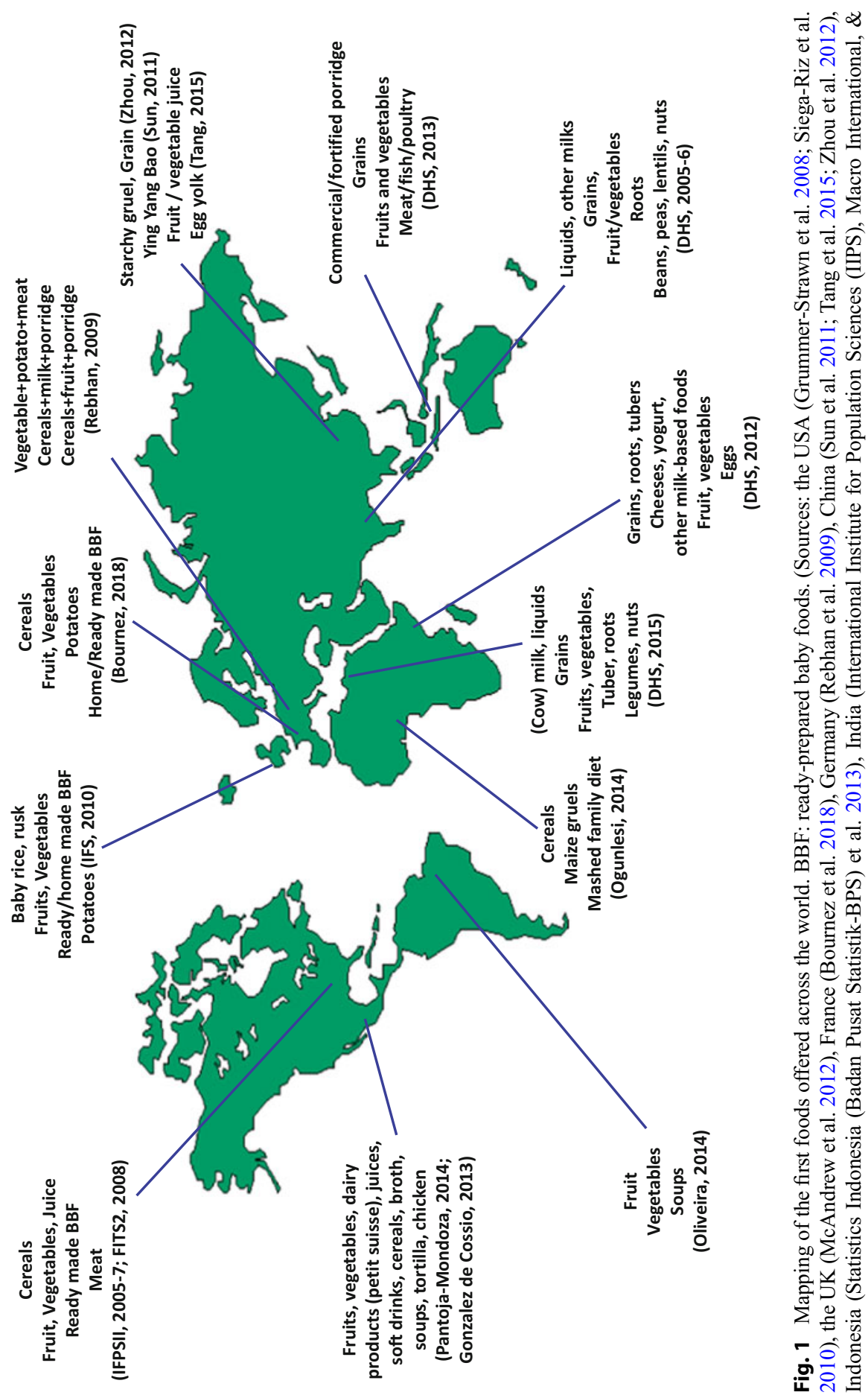


expect agreement in food likes, revealing a social agreement model, in which infants expect a generalization of food preferences among people eating the same foods, especially if they share the same language (Liberman et al. 2016).

Role of the environment. The previous observation drives to underline the power of the social environment in the shaping of children's eating behavior (Savage et al. 2007). The younger the children, the less autonomous they are in terms of drinking and eating; meaning, they need to receive social support to drink and eat properly. This is strongly shaping what and how much children eat (Shutts et al. 2013). For instance, research has shown that infants aged between 7 and 14 weeks drink more formula in the presence of social interactions, revealing the power of social reinforcement at a very early stage (Lumeng et al. 2007). The mechanisms behind social eating are multiple: when infants are old enough, eating together enables sharing the same foods, which provides an opportunity for the repeated exposures learning mechanism to take place. Moreover, this provides a context for visual imitation. Eating together is also accompanied by conversations at the meal table, which may have the power to define likes and dislikes even at a very early stage of food discoveries (Wiggins 2019). Altogether, social eating in early childhood is a context for "emotional pervasion": language may help develop knowledge and social norms about what is "good for children" to eat which could sustain the pleasure from eating specific foods related to their sensory properties (i.e., children's perceptions of whether the food is "good to them" to eat). During this very early stage in life (as also later in life!), pleasure from eating is partly constructed by interactions with others and socially produced (Marty et al. 2018a).

\section{The Preschool Age: A Neophobic Phase, Source of Family Tensions}

Sensory capacities and cognitive development. At around the end of the second year of life, children start demonstrating strong neophobic reactions, when presented with unknown foods (Dovey et al. 2008; Nicklaus and Monnery-Patris 2018; Taylor et al. 2015). They may also demonstrate rejection reactions when offered foods they previously ate without problem. This type of neophobic behavior is a source of questioning for parents and researchers alike. Very often, this neophobic temperament is associated with a low consumption of fruit and vegetables. Some researchers suggested that this type of eating behavior could be related to a specific sensitivity to flavors, as measured by a psychometric scale evaluating "sensory sensitivity" through parental report in children aged 2-5 years old (Coulthard and Blissett 2009). Further

Fig. 1 (continued) 2007 2007), Ethiopia (Central Statistical Agency [Ethiopia] and ICF International 2012), Egypt (Ministry of Health and Population [Egypt] et al. 2015), Nigeria (Ogunlesi et al. 2014), Brazil (Oliveira et al. 2014), Mexico (Gonzalez de Cossio et al. 2013; Pantoja-Mendoza et al. 2014)) 
work helped to refine this observation based on children's behavioral observations while tasting or smelling actual food tastants or odorants, showing that a higher reactivity to food smells but not to food tastes was associated with a higher neophobia score (Monnery-Patris et al. 2015). Beyond this sensory-based interpretation of the development of neophobic behavior in children, other aspects of cognitive development could account for this evolution. It has been proposed that neophobic behaviors could be adaptive to prevent the child from ingesting noxious foods once the child becomes autonomous and mobile enough to reach for foods (or objects) from the environment, without the supervision of parents or caregivers (Nicklaus and Monnery-Patris 2018). Cognitively speaking, food neophobia also seems to parallel the development of categorization abilities in children (Lafraire et al. 2016). The use of the "no" frequently associated with neophobic reactions (or rejection of some food items) can also be interpreted in relation to the emerging awareness by children of their distinction from their parents (especially their mother). They are learning during this phase to manipulate a new power, which has strong consequences on their social environment.

Food likes and dislikes. Studies conducted right at the beginning of the neophobic period show that by 2 or 3 years of age, children have established firms likes and dislikes (Nicklaus et al. 2005b) and start making less varied food choices despite the increase in their absolute nutritional needs probably in relation to their likes and dislikes (Nicklaus et al. 2005c), and their patterns of likes/dislikes are quite stable throughout childhood and adolescence (Nicklaus et al. 2004, 2005a). For instance, these studies show that the children who chose vegetables most frequently at 2-3 years were also those who consumed a higher variety of vegetables up to the age of 22 years. Thus, most likes and dislikes could be formed at an early stage during childhood and could be relatively stable through childhood. This does not preclude learning at all ages during childhood, as shown in many studies with older children, or even adults. Given the high plasticity of the affective system controlling the food system, food preferences may also find their origin in early dietary exposure. For instance, preschool-aged children may prefer more sour beverages if they had been exposed to a specific formula milk with distinct taste properties, such as extensively hydrolyzed cow milk protein formula, which may taste bitter or sour (Mennella and Beauchamp 2002). Thus, variations in flavor preferences during the preschool period may find their origin in early dietary exposures during the first years of life.

The immediate consequence of food neophobia is the fact that food or beverage likes and dislikes during this period are strongly influenced by the degree of familiarity of the child with the food or beverage. Repeated exposures may help overcome neophobic reactions, if foods are actually tasted and not only visually exposed to children (Birch et al. 1987), but the effect of repeated exposures seems to attenuate as children grow in age (Caton et al. 2014). In this study, repeated exposures to a new vegetable (artichoke) were associated with a high food consumption and to a high increase in consumption after exposure in children in their first year, but these effects were attenuated in children in their second or third year. This suggests a lower flexibility in terms of learning to like a new food as children 
grow into preschool age. Because of repeated exposures which still appear as a robust mechanism for learning, children learn to like the specific features of a food they are exposed to. For instance, children who had been exposed to salty or sweet tofu learn to prefer the version they had been exposed to, but not the other versions (Sullivan and Birch 1990). Although the repeated exposure mechanism is theoretically well described, reviews on its effects show small effect sizes when looking at the evolution of specific food acceptance, such as vegetables (Appleton et al. 2018). Other strategies to enhance children's vegetable acceptance, such as parental education, are not more successful (Hodder et al. 2018).

Attitudes and thinking. During the preschool stage, children start developing an abstract reasoning about foods (Michela and Contento 1986; Roedder 1999); executive functions develop, as well as brand representations (McAlister and Cornwell 2010). The emergence of more developed mental representations about foods may also be associated with side effects: for instance, children learn to associate "good for health" with "bad taste," for instance, when they are asked to eat vegetables, which taste bad to them, because "they are good for them." This may create unwanted expectations in such a way that a given product (a sweet beverage, in this study) labeled as "good for health" is less liked by children than when it has no label (Wardle and Huon 2000). Similarly, foods that are said by caregivers to "make you strong" are less eaten than foods with no label (Maimaran and Fishbach 2014). Would such unwanted expectations about the relationship between "good for you" and "bad taste" be observed in non-Western cultures? This is, to the best of our knowledge, not documented; but it is likely that any type of contradiction between information provided related to a food and individual preference is likely to produce a decrease in liking, as shown also in adults. So at this early stage in life, it appears clearly that health-oriented arguments are not a good strategy to encourage the consumption of a given food. Indeed in many studies, applying such strategies in the family context to encourage the consumption of foods is generally associated with a lower willingness to taste such foods, but in such studies it is difficult to tear apart cause and consequences. It may very well be that parents use more bribing strategies to make children taste a food when they know that their child has previously shown rejection reactions to this food and/or when they consider that this food has a specific nutritional interest (e.g., vegetable). But if these foods with specific interest are also foods which generally taste bad to children (e.g., vegetable), the application to bribing strategies may be critical in generating negative expectations about the food, resulting in a negative spiral likely to create (unwanted) educational tensions at the family table.

Role of the environment including parental feeding practices. As suggested above, another important consequence of the emergence of a peak of neophobic reactions in children is the feeding strategies adopted by parents to encourage their children to eat the rejected foods. Because neophobic reactions are often observed in reaction to the presentation of foods such as vegetables and fruit, and because most parents are aware of the health values and of the importance of consumption of such foods to maintain a healthy status, often the strategies employed by parents are applied to the same types of foods (Savage et al. 2007). (Of note, this observation 
cannot be generalized across the full socioeconomic gradient, since some research studies have clearly shown that in families with a lower socioeconomic status, the foods preferentially fed to children are unhealthy, indulgent foods that are perceived to be the only affordable option by parents (Fielding-Singh and Wang 2017).) Research has long shown that such strategies, such as coercion, bribing, or forcing, can have counterproductive effect by generating a negative context around eating, which acts as an unconditioned stimulus to condition rejection of the food (Savage et al. 2007). In some circumstances, rewarding the consumption of a target food with a small, nonfood reward could have a positive effect (Cooke et al. 2011). However, it is now considered that repeated exposures alone, without reward, should be the best way to promote the development of liking for a given food, even if its effects are of small amplitude (Appleton et al. 2018; Hodder et al. 2018). On the contrary, parents may also wish to restrict access for foods which are either specifically liked by children or considered "unhealthy." In this case again, the application of restriction may increase the desire to eat the "forbidden" food (Fisher and Birch 1999; Jansen et al. 2008).

During the preschool period, children start attending daycare, or preschool, depending on each country's schooling organization. This creates the condition for socialization effects to take place, and research indeed shows that social modeling has a strong effect on willingness to taste unknown foods. For instance, children are more willing to taste unfamiliar foods if adults are also eating the food (Addessi et al. 2005; Harper and Sanders 1975), if peers declare that they like the food (Greenhalgh et al. 2009; Hendy 2002), and if peers may even be more influential than adults (Frazier et al. 2012; Hendy and Raudenbush 2000). Research also showed the influence of the presence of other children on the level of food consumption: preschool children ate more pizza in groups of nine than in groups of three individuals (Lumeng and Hillman 2007). At this age children become sensitive to portion size, meaning that they eat more when larger food portions are presented to them (Reale et al. 2019).

\section{School Age: A Curious, Autonomous Eater Still Framed by Parental Practices}

When approaching school age, reasoning and reading abilities increase which facilitate the conduct of studies with children; hence many studies have focused on this age range.

Sensory capacities. While it becomes easier to study sensory perceptions as children grow older (Nicklaus 2015), the most relevant knowledge related to development of sensory aspects of eating relates to sensory preferences in children, not to perceptions. Studies show that children aged 6-12 years old find sweeter variants of beverages less sweet than teenagers or adults but prefer them (Zandstra and de Graaf 1998) and that preadolescents have a more marked preference for very sweet solutions than adults (Desor et al. 1975). When the kids were followed up to early adulthood, their preferred level of sweet taste was lower than when they were 
preteens, revealing a change in affective tone for very sweet products (Desor and Beauchamp 1987). Rejection of bitterness of common substances (urea, caffeine, tetralone) is observed in school-age children and is indeed applied in practice by the addition of bitter substances (tetralone or Bitrex(C) to home care products to deter their consumption by children (Mennella et al. 2003). The taste of a food may influence how much children can like it. For instance, children can get to like a sweet orangeade after eight exposures, but not a sour orangeade (Liem and de Graaf 2004). Sensitivity to bitterness may strongly influence liking for bitter foods: children who are more sensitive to PROP or 6- $n$-propylthiouracyl more frequently refuse vegetables, which may taste bitter, than nonsensitive children. This was confirmed for spinach (Turnbull and Matisoo-Smith 2002) and broccoli (Keller et al. 2002), but the association is not systematically observed (Anliker et al. 1991). Similarly, children who like sourness (boys, in that study) may also like sour fruits more than children who don't like sourness (Liem et al. 2006). Saltiness may also influence how much children like and consume foods but has a minor influence compared to level of hunger, which is the $\mathrm{n}^{\circ} 1$ factor to explain level of food intake (Bouhlal et al. 2013).

Likes and dislikes. The influence of hunger on food choices leads to considering the importance of energy density in driving children food preferences and energy intake control. It was indeed shown, in sweet-flavored beverages which were caloric or not (based on use of sucrose or sucralose, a nonnutritive sweetener), that energy density seems to condition more stable flavor preferences than sweetness alone (Remy et al. 2014). Furthermore, this study shows that energy density is not detected on the short term after consumption (i.e., within 1 hour post consumption of a new beverage) but is learned through repeated exposures. This suggests the importance of providing foods with a constant flavor-energy density association, in order to facilitate appropriate food intake control in children and adaptive flavor preference learning. However, it is very likely that by school age, children have already developed their main food repertoire and developed marked food likes and dislikes which may strongly influence their food choices. They have extensive knowledge about meal structure, type of foods likely to be offered at a given meal (Birch et al. 1984). This implicit knowledge can guide children in making choices to optimize liking level through a competitive range of foods which may vary in terms of healthiness (Marty et al. 2018b).

Attitudes and thinking. As underlined previously, cognitive abilities evolve strongly with age, and this has been especially studied in the context of understanding the effect of cognitive cues on food decision-making, for instance, in the context of food advertisement and marketing (Story and French 2004). Credence cues as those used in (food) advertisement are likely to influence choice behavior. Before the age of $7 / 8$ years, children tend to view ads as entertaining and informative, which makes them very vulnerable to ads (McAlister and Cornwell 2010; Michela and Contento 1986; Roedder 1999). After this age, children begin to understand the persuasive intent of ads but can still be persuaded by the emotive message of ads. Credence cues from representations and expectations, which are likely to modulate experiences pleasure (Fernqvist and Ekelund 2014). In children as in adults, brands 
have a positive effect on liking, which may be modulated by socioeconomic status (Sosa and Hough 2006). Thus, the presence of licensed characters has a positive effect on liking, as revealed also in preschool children (Roberto et al. 2010). The use of such characters may be more influential than the application of cognitive information about nutritional content to alter children's evaluations of foods, which may be effective in health-concerned children only (Engell et al. 1998).

The emergence of mental representations about foods makes it possible to consider the manipulation of these representations to modify food choices, if one admits the connection between intentions and actions. In other words, it may be possible to orientate children's food choices by making choice option more or less salient in children's mind, by manipulating cues in the environment that are likely to "prime" mental representation of these foods (Chambaron et al. 2015; Gaillet et al. 2013). Following on this idea, one study attempted to prime mental representations of healthy versus unhealthy foods in children by using olfactory primes (respectively, a pear odor to prime "healthy foods" and a pound cake odor to prime "unhealthy foods") and evaluated whether the presence of these olfactory primes would be associated with different choices for healthy versus unhealthy foods and whether the effect of the olfactory primes on food choices would be different in children with or without overweight (Marty et al. 2017a). In children with obesity, the fruity odor increased the likelihood of a fruit to be chosen compared to the noodor condition, while the fatty-sweet odor had no effect on food choice. In children without obesity, both the fruity and the fatty-sweet odors decreased the likelihood to choose a fruit compared to the no-odor condition. The different patterns of results obtained in both groups of children suggest differences in the mental representations activated by non-attentively perceived olfactory cues based on weight status. This suggests important differences in attitudes toward eating associated with weight status, which were either pre-existing the development of overweight or resulting from the overweight status. Thus, the development of obesity with age is not only associated with physiological and psychological adverse effects but also to modifications of mental representation of foods which are likely to alter food choices in everyday situation.

Attitudes toward eating can also evolve because of the development of individual relationships with foods and eating (independently from weight status). Affective attitudes toward foods develop in parallel to cognitive attitudes and could be influential in determining food choices. For instance, children's attitudes were defined as nutritionally oriented versus hedonically oriented and evaluated with a direct task or an indirect task (Monnery-Patris et al. 2016). With development, the direct task (food categorization) showed a significant increase in nutrition-driven categorizations with school level, but the indirect task showed an increase in hedonically oriented attitudes, in relation to the children learning culinary scripts in his/her environment. This reveals that with development, children increase their nutrition knowledge (and are able to report so accordingly) but when asked less directly also reveal an increasing dominance of affective-based relationship to food. To note, a complementary study looking at food choices and their associations with affective or cognitive attitudes showed that children with high nutritionally oriented 
attitudes (whether they were studied directly or indirectly) made a lower number of healthy food choices when they were offered the possibility to choose among snack foods of differing healthiness values (Marty et al. 2017c). This observation that nutritionally oriented attitudes were not associated with a higher choice of healthy foods may suggest that on the contrary, hedonically orientated attitudes could help children make healthy food choices when healthy versus unhealthy choices are equally likely or in other words that pleasure of eating could be favorable to healthier choices in some circumstances.

This method to study attitudes also revealed differences among children according to weight status (Marty et al. 2017b). There was no difference in nutritionally oriented attitudes with the indirect task, but with the direct task, children with overweight or obesity revealed more nutritionally oriented attitudes than normal-weight children. This could be related to the tentative management of their overweight by their caregivers, which could drive them to declare more attention toward the nutritional aspect of eating.

Role of the environment. These few examples illustrate how children's representation about foods can be modified with development, in relation to the immersion in the social milieu in which children live. As noted by P. Fielding-Singh, "whereas low-SES parents use food to buffer against deprivation, high-SES parents provision foods to fulfill classed values around health and parenting" (Fielding-Singh 2017). Children incorporate social norms about which foods are relevant to eat in which situation, and they can adjust the food choices they make to various social situations (Marty et al. 2018b). Clearly, even at this early age, food choice decisions increase in complexity as they can be influenced by pleasure, interactions with parents, sibling, social norms, marketing messages, etc. (Lapierre et al. 2017). Mapping the role of the environment in this context becomes more difficult because it becomes almost as complex as in adults. In children as in adults, the environment in which choices are made can influence food choice. This aspect of the choice environment was explored to evaluate the effect of nudging strategies on food choices. Nudges (e.g., "any aspect of the choice architecture that alters people's behavior in a predictable way (1) without forbidding any options or (2) significantly changing their economic incentives" Thaler \& Sunstein 2008, in (Cadario and Chandon 2019)) intend to make foods more or less salient, in order to facilitate or hinder food choice. Nudges applied to encourage healthy eating have proven as successful to increase healthy food choices in children as in adults (Cadario and Chandon 2019). However, modification of the food offer is not always sufficient to promote healthy eating. Providing more choice between different types of vegetables to children was seen as a means to increase their consumption and liking, because this could increase self-efficacy and feelings of autonomy (Zeinstra et al. 2010). However, in this study, the provision of more choice options was appreciated by children but did not result in an increase in vegetable liking or consumption.

Other nudging studies prime the social norms around the food consumption in order to encourage healthy eating. One study, for instance, delivered information to children suggesting that other children had eaten a large amount of carrots, no carrots, or control information (Sharps and Robinson 2015). Children ate more 
carrots when they believed that other children had eaten a large amount of carrots, compared to all other conditions. This example shows that perceived social norms can influence healthy eating in children. This is not always pushing children toward healthier food choices. For instance, when children are asked to choose foods for a birthday party among a selection of healthy versus unhealthy foods, they are much more likely to choose unhealthy options than when make food choice for a nutrition class (Marty et al. 2018b)!

During school age, children are given more and more autonomy regarding food purchasing, and their buying strategy develop (Hartmann et al. 2017). They buy the brand they like rather than the brands they know, and they become price-sensitive. This may open ways to encourage healthy eating by applying price increase for energy-dense, unhealthy foods. However, the long-term consequences of such strategies on mental representations of healthy versus unhealthy foods are unknown. Clearly, more research is needed to understand the effect of the environment (including social media) on twenty-first century's children's eating and drinking behavior and the conditions under which healthy and sustainable food choices are made.

\section{Conclusions}

In conclusion, drinking and eating in childhood bear a special significance considering that eating behavior is learned and that most of this learning process takes place during the early years, forming enduring memories, for the best or for the worst. Thus, early drinking and eating experience may program both food preferences and the health status of the adult. However, in relation to the importance of sensory inputs for children, and of pleasure from eating, childhood is also a period when pleasure plays a prominent role in orienting food choices. When growing into school age, children's food choices can be modulated by attitudes and social norms and start to recompose because of the internalization of social norms related to eating and drinking.

\section{References}

Addessi, E., Galloway, A. T., Visalberghi, E., \& Birch, L. L. (2005). Specific social influences on the acceptance of novel foods in 2-5-year-old children. Appetite, 45(3), 264-271.

Anliker, J. A., Bartoshuk, L., Ferris, A. M., \& Hooks, L. D. (1991). Children's food preferences and genetic sensitivity to the bitter taste of $6-n$-propylthiouracil (PROP). The American Journal of Clinical Nutrition, 54(2), 316-320.

Appleton, K. M., Hemingway, A., Rajska, J., \& Hartwell, H. (2018). Repeated exposure and conditioning strategies for increasing vegetable liking and intake: Systematic review and meta-analyses of the published literature. The American Journal of Clinical Nutrition, 108(4), 842-856. https://doi.org/10.1093/ajen/nqy143.

Beauchamp, G. K., \& Mennella, J. A. (2011). Flavor perception in human infants: Development and functional significance. Digestion, 83, 1-6. https://doi.org/10.1159/000323397. 
Birch, L. L., Billman, J., \& Richards, S. S. (1984). Time of day influences food acceptability. Appetite, 5, 109-116.

Birch, L. L., McPhee, L., Shoba, B. C., Pirok, E., \& Steinberg, L. (1987). What kind of exposure reduces children's food neophobia? Looking vs. tasting. Appetite, 9(3), 171-178.

Bouhlal, S., Chabanet, C., Issanchou, S., \& Nicklaus, S. (2013). Salt content impacts food preferences and intake among children. PLoS One, 8(1), e53971. https://doi.org/10.1371/journal.pone.0053971.

Bournez, M., Ksiazek, E., Wagner, S., Kersuzan, C., Tichit, C., Gojard, S., ... Nicklaus, S. (2018). Factors associated with the introduction of complementary feeding in the French ELFE cohort study. Maternal and Child Nutrition, 14(2), e12536. https://doi.org/10.1111/mcn.12536.

Burnier, D., Dubois, L., \& Girard, M. (2011). Exclusive breastfeeding duration and later intake of vegetables in preschool children. European Journal of Clinical Nutrition, 65(2), 196-202.

Cadario, R., \& Chandon, P. (2019). Which healthy eating nudges work best? A meta-analysis of field experiments. Marketing Science. https://doi.org/10.1287/mksc.2018.1128.

Caton, S. J., Blundell, P., Ahern, S. M., Nekitsing, C., Olsen, A., Møller, P., .. . Hetherington, M. M. (2014). Learning to eat vegetables in early life: The role of timing, age and individual eating traits. PLoS One, 9(5), e97609. https://doi.org/10.1371/journal.pone.0097609.

Central Statistical Agency [Ethiopia], \& ICF International. (2012). Ethiopia Demographic and Health Survey 2011. In C. S. A. a. I. International (Ed.), (pp. 450). Addis Ababa, Ethiopia and Calverton, Maryland.

Chambaron, S., Chisin, Q., Chabanet, C., Issanchou, S., \& Brand, G. (2015). Impact of olfactory and auditory priming on the attraction to foods with high energy density. Appetite, 95, 74-80. https://doi.org/10.1016/j.appet.2015.06.012.

Cooke, L. J., Chambers, L. C., Añez, E. V., \& Wardle, J. (2011). Facilitating or undermining? The effect of reward on food acceptance. A narrative review. Appetite, 57(2), 493-497. https://doi.org/10.1016/j.appet.2011.06.016.

Coulthard, H., \& Blissett, J. (2009). Fruit and vegetable consumption in children and their mothers: moderating effects of child sensory sensitivity. Appetite, 52(2), 410-415

Coulthard, H., Harris, G., \& Fogel, A. (2014). Exposure to vegetable variety in infants weaned at different ages. Appetite, 78(0), 89-94. https://doi.org/10.1016/j.appet.2014.03.021.

de Lauzon-Guillain, B., Jones, L., Oliveira, A., Moschonis, G., Betoko, A., Lopes, C., . . Charles M. A. (2013). The influence of early feeding practices on fruit and vegetable intake among preschool children in 4 European birth cohorts. The American Journal of Clinical Nutrition, 98 (3), 804-812. https://doi.org/10.3945/ajcn.112.057026.

Demonteil, L., Tournier, C., Marduel, A., Dusoulier, M., Weenen, H., \& Nicklaus, S. (2019). Longitudinal study on acceptance of food textures between 6 and 18 months. Food Quality and Preference, 71, 54-65. https://doi.org/10.1016/j.foodqual.2018.05.010.

Desor, J. A., \& Beauchamp, G. K. (1987). Longitudinal changes in sweet preferences in humans. Physiology \& Behavior, 39, 639-641.

Desor, J. A., Greene, L. S., \& Maller, O. (1975). Preference for sweet and salty in 9- to 15-year-old and adult humans. Science, 190, 686-687.

Dovey, T. M., Staples, P. A., Gibson, E. L., \& Halford, J. C. G. (2008). Food neophobia and 'picky/fussy' eating in children: A review. Appetite, 50(2-3), 181-193.

Engell, D., Bordi, P., Borja, M., Lambert, C., \& Rolls, B. (1998). Effects of information about fat content on food preferences in pre-adolescent children. Appetite, 30(3), 269-282. https://doi. org/10.1006/appe.1997.0106.

English, L. K., Obbagy, J. E., Wong, Y. P., Butte, N. F., Dewey, K. G., Fox, M. K., . . Stoody, E. E. (2019). Timing of introduction of complementary foods and beverages and growth, size, and body composition: A systematic review. The American Journal of Clinical Nutrition, 109 (Supplement_7), 935S-955S. https://doi.org/10.1093/ajcn/nqy267.

Fallon, A. E., Rozin, P., \& Pliner, P. (1984). The child's conception of food: The development of food rejections with special reference to disgust and contamination sensitivity. Child Development, 55(2), 566-575. 
Fernqvist, F., \& Ekelund, L. (2014). Credence and the effect on consumer liking of food - A review. Food Quality and Preference, 32, 340-353. https://doi.org/10.1016/j.foodqual.2013.10.005.

Fewtrell, M., Bronsky, J., Campoy, C., Domellof, M., Embleton, N., Fidler Mis, N., ... Molgaard, C. (2017). Complementary feeding: A position paper by the European Society for Paediatric Gastroenterology, hepatology, and nutrition (ESPGHAN) committee on nutrition. Journal of Pediatric Gastroenterology and Nutrition, 64(1), 119-132. https://doi.org/10.1097/ MPG.0000000000001454.

Fielding-Singh, P. (2017). A taste of inequality: Food's symbolic value across the socioeconomic Spectrum. Sociological Science, 4, 424-448. https://doi.org/10.15195/v4.a17.

Fielding-Singh, P., \& Wang, J. (2017). Table talk: How mothers and adolescents across socioeconomic status discuss food. Social Science \& Medicine, 187, 49-57. https://doi.org/10.1016/j. socscimed.2017.06.016.

Fildes, A., Lopes, C., Moreira, P., Moschonis, G., Oliveira, A., Mavrogianni, C., ... Cooke, L. (2015). An exploratory trial of parental advice for increasing vegetable acceptance in infancy. British Journal of Nutrition, 114(2), 328-336.

Fisher, J. O., \& Birch, L. L. (1999). Restricting access to palatable foods affects children's behavioral response, food selection, and intake. American Journal of Clinical Nutrition, 69 (6), 1264-1272.

Frazier, B. N., Gelman, S. A., Kaciroti, N., Russell, J. W., \& Lumeng, J. C. (2012). I'll have what she's having: The impact of model characteristics on children's food choices. [Research Support, N.I.H., Extramural]. Developmental Science, 15(1), 87-98. https://doi.org/10.1111/ j.1467-7687.2011.01106.x.

Gaillet, M., Sulmont-Rosse, C., Issanchou, S., Chabanet, C., \& Chambaron, S. (2013). Priming effects of an olfactory food cue on subsequent food-related behaviour. Food Quality and Preference, 30(2), 274-281. https://doi.org/10.1016/j.foodqual.2013.06.008.

Gerrish, C. J., \& Mennella, J. A. (2001). Flavor variety enhances food acceptance in formula-fed infants. American Journal of Clinical Nutrition, 73(6), 1080-1085.

Gonzalez de Cossio, T., Escobar-Zaragoza, L., Gonzalez-Castell, D., Reyes-Vazquez, H., \& RiveraDommarco, J. A. (2013). Breastfeeding in Mexico was stable, on average, but deteriorated among the poor, whereas complementary feeding improved: Results from the 1999 to 2006 National Health and Nutrition Surveys. [Research Support, Non-U.S. Gov't]. The Journal of Nutrition, 143(5), 664-671. https://doi.org/10.3945/jn.112.163097.

Greenhalgh, J., Dowey, A. J., Horne, P. J., Fergus Lowe, C., Griffiths, J. H., \& Whitaker, C. J. (2009). Positive- and negative peer modelling effects on young children's consumption of novel blue foods. Appetite, 52(3), 646-653.

Grummer-Strawn, L. M., Scanlon, K. S., \& Fein, S. B. (2008). Infant feeding and feeding transitions during the first year of life. Pediatrics, 122(Suppl 2), S36-S42. https://doi.org/10.1542/ peds.2008-1315d.

Haller, R., Rummel, C., Henneberg, S., Pollmer, U., \& Köster, E. P. (1999). The influence of early experience with vanillin on food preference later in life. Chemical Senses, 24(4), 465-467.

Harper, L. V., \& Sanders, K. M. (1975). The effect of adults' eating on young children's acceptance of unfamiliar foods. Journal of Experimental Child Psychology, 20(2), 206-214.

Hartmann, M., Cash, S. B., Yeh, C. H., Landwehr, S. C., \& McAlister, A. R. (2017). Children's purchase behavior in the snack market: Can branding or lower prices motivate healthier choices? Appetite, 117, 247-254. https://doi.org/10.1016/j.appet.2017.06.014.

Hausner, H., Nicklaus, S., Issanchou, S., Mølgaard, C., \& Møller, P. (2010). Breastfeeding facilitates acceptance of a novel dietary flavour compound. Clinical Nutrition, 29(1), 141-148.

Hendy, H. M. (2002). Effectiveness of trained peer models to encourage food acceptance in preschool children. Appetite, 39(3), 217-225.

Hendy, H. M., \& Raudenbush, B. (2000). Effectiveness of teacher modeling to encourage food acceptance in preschool children. Appetite, 34(1), 61-76. 
Hepper, P. G., Wells, D. L., Dornan, J. C., \& Lynch, C. (2013). Long-term flavor recognition in humans with prenatal garlic experience. Developmental Psychobiology, 55(5), 568-574. https://doi.org/10.1002/dev.21059.

Hodder, R. K., Stacey, F. G., O’Brien, K. M., Wyse, R. J., Clinton-McHarg, T., Tzelepis, F., ... Wolfenden, L. (2018). Interventions for increasing fruit and vegetable consumption in children aged five years and under. Cochrane Database of Systematic Reviews, 1, CD008552. https://doi. org/10.1002/14651858.CD008552.pub4.

Inoue, M., \& Binns, C. W. (2014). Introducing solid foods to infants in the Asia Pacific region. Nutrients, 6(1), 276-288. https://doi.org/10.3390/nu6010276.

International Institute for Population Sciences (IIPS), Macro International, \& 2007. (2007). National Family Health Survey (NFHS-3), 2005-06: India: Volume I. In International Institute for Population Sciences (Ed.), (pp. 765). Mumbai.

Jansen, E., Mulkens, S., Emond, Y., \& Jansen, A. (2008). From the Garden of Eden to the land of plenty: Restriction of fruit and sweets intake leads to increased fruit and sweets consumption in children. Appetite, 51(3), 570-575.

Keller, K. L., Steinmann, L., Nurse, R. J., \& Tepper, B. J. (2002). Genetic taste sensitivity to 6n-propylthiouracil influences food preference and reported intake in preschool children. Appetite, 38(1), 3-12.

Lafraire, J., Rioux, C., Giboreau, A., \& Picard, D. (2016). Food rejections in children: Cognitive and social/environmental factors involved in food neophobia and picky/fussy eating behavior. Appetite, 96, 347-357. https://doi.org/10.1016/j.appet.2015.09.008.

Lange, C., Visalli, M., Jacob, S., Chabanet, C., Schlich, P., \& Nicklaus, S. (2013). Maternal feeding practices during the first year and their impact on infants' acceptance of complementary food. Food Quality and Preference, 29(2), 89-98. https://doi.org/10.1016/j.foodqual.2013.03.005.

Lapierre, M. A., Fleming-Milici, F., Rozendaal, E., McAlister, A. R., \& Castonguay, J. (2017). The effect of advertising on children and adolescents. Pediatrics, 140(Suppl 2), S152-S156. https://doi.org/10.1542/peds.2016-1758V.

Liberman, Z., Woodward, A. L., Sullivan, K. R., \& Kinzler, K. D. (2016). Early emerging system for reasoning about the social nature of food. Proceedings of the National Academy of Sciences of the United States of America, 113(34), 9480-9485. https://doi.org/10.1073/pnas.1605456113.

Liem, D. G., \& de Graaf, C. (2004). Sweet and sour preferences in young children and adults: Role of repeated exposure. Physiology \& Behavior, 83(3), 421-429.

Liem, D. G., Bogers, R. P., Dagnelie, P. C., \& de Graaf, C. (2006). Fruit consumption of boys (8-11 years) is related to preferences for sour taste. Appetite, 46(1), 93-96.

Lipchock, S. V., Reed, D. R., \& Mennella, J. A. (2011). The Gustatory and olfactory systems during infancy: implications for development of feeding behaviors in the high-risk neonate. Clin Perinatol, 38(4), 627-+. https://doi.org/10.1016/j.clp.2011.08.008.

Lumeng, J. C., \& Hillman, K. H. (2007). Eating in larger groups increases food consumption. Archives of Disease in Childhood, 92(5), 384-387. https://doi.org/10.1136/adc.2006.103259.

Lumeng, J. C., Patil, N., \& Blass, E. M. (2007). Social influences on formula intake via suckling in 7 to 14-week-old-infants. Developmental Psychobiology, 49(4), 351-361. https://doi.org/10.10 02/dev.20221.

Maier, A., Chabanet, C., Schaal, B., Issanchou, S., \& Leathwood, P. (2007). Effects of repeated exposure on acceptance of initially disliked vegetables in 7-month old infants. Food Quality and Preference, 18(8), 1023-1032.

Maier, A. S., Chabanet, C., Schaal, B., Leathwood, P. D., \& Issanchou, S. N. (2008). Breastfeeding and experience with variety early in weaning increase infants' acceptance of new foods for up to two months. Clinical Nutrition, 27(6), 849-857.

Maier-Nöth, A., Schaal, B., Leathwood, P., \& Issanchou, S. (2016). The lasting influences of early food-related variety experience: A longitudinal study of vegetable acceptance from 5 months to 6 years in two populations. PLoS One, 11(3), e0151356. https://doi.org/10.1371/journal. pone. 0151356 . 
Maimaran, M., \& Fishbach, A. (2014). If it's useful and you know it, do you eat? Preschoolers refrain from instrumental food. Journal of Consumer Research, 41(3), 642-655. https://doi.org/ $10.1086 / 677224$.

Mallan, K. M., Fildes, A., Magarey, A. M., \& Daniels, L. A. (2016). The relationship between number of fruits, vegetables, and noncore foods tried at age 14 months and food preferences, dietary intake patterns, fussy eating behavior, and weight status at Age 3.7 years. [article]. Journal of the Academy of Nutrition and Dietetics, 116(4), 630-637. https://doi.org/10.1016/j. jand.2015.06.006.

Marlier, L., Schaal, B., \& Soussignan, R. (1998). Bottle-fed neonates prefer an odor experienced in utero to an odor experienced postnatally in the feeding context. Developmental Psychobiology, 33(2), 133-145.

Marty, L., Bentivegna, H., Nicklaus, S., Monnery-Patris, S., \& Chambaron, S. (2017a). Nonconscious effect of food Odors on Children's food choices varies by weight status. Frontiers in Nutrition, 4. https://doi.org/10.3389/Fnut.2017.00016.

Marty, L., Chambaron, S., Bournez, M., Nicklaus, S., \& Monnery-Patris, S. (2017b). Comparison of implicit and explicit attitudes towards food between normal- and overweight French children. Food Quality and Preference, 60, 145-153. https://doi.org/10.1016/j.foodqual.2017.04.013.

Marty, L., Miguet, M., Bournez, M., Nicklaus, S., Chambaron, S., \& Monnery-Patris, S. (2017c). Do hedonic-versus nutrition-based attitudes toward food predict food choices? A cross-sectional study of 6-to 11-year-olds. International Journal of Behavioral Nutrition and Physical Activity, 14, 162. https://doi.org/10.1186/S12966-017-0618-4.

Marty, L., Chambaron, S., Nicklaus, S., \& Monnery-Patris, S. (2018a). Learned pleasure from eating: An opportunity to promote healthy eating in children? Appetite, 120, 265-274. https://doi.org/10.1016/j.appet.2017.09.006.

Marty, L., Nicklaus, S., Miguet, M., Chambaron, S., \& Monnery-Patris, S. (2018b). When do healthiness and liking drive children's food choices? The influence of social context and weight status. Appetite, 125, 466-473. https://doi.org/10.1016/j.appet.2018.03.003.

McAlister, A. R., \& Cornwell, T. B. (2010). Children's Brand symbolism understanding: Links to theory of mind and executive functioning. Psychology \& Marketing, 27(3), 203-228. https://doi.org/10.1002/mar.20328.

McAndrew, F., Thompson, J., Fellows, L., Large, A., Speed, M., \& Renfrew, M. J. (2012). Infant feeding survey 2010 consolidated report (p. 331). Dundee: Health and Social Care Information Centre.

Mennella, J. A., \& Beauchamp, G. K. (2002). Flavor experiences during formula feeding are related to preferences during childhood. Early Human Development, 68(2), 71-82.

Mennella, J. A., Jagnow, C. P., \& Beauchamp, G. K. (2001). Prenatal and postnatal flavor learning by human infants. Pediatrics, 107(6), e88.

Mennella, J. A., Pepino, M. Y., \& Beauchamp, G. K. (2003). Modification of bitter taste in children. Developmental Psychobiology, 43(2), 120-127.

Mennella, J. A., Nicklaus, S., Jagolino, A. L., \& Yourshaw, L. M. (2008). Variety is the spice of life: Strategies for promoting fruit and vegetable acceptance during infancy. Physiology \& Behavior, 94(1), 29-38.

Michela, J. L., \& Contento, I. R. (1986). Cognitive, motivational, social, and environmental influences on children's food choices. Health Psychology, 5(3), 209-230.

Ministry of Health and Population [Egypt], El-Zanaty and Associates [Egypt], \& ICF International. (2015). Egypt Demographic and Health Survey 2014. In M. o. H. a. P. a. I. International (Ed.), (p. 463). Cairo, Egypt and Rockville, Maryland.

Monnery-Patris, S., Wagner, S., Rigal, N., Schwartz, C., Chabanet, C., Issanchou, S., \& Nicklaus, S. (2015). Smell differential reactivity, but not taste differential reactivity, is related to food neophobia in toddlers. Appetite, 95, 303-309. https://doi.org/10.1016/j.appet.2015.07.021.

Monnery-Patris, S., Marty, L., Bayer, F., Nicklaus, S., \& Chambaron, S. (2016). Explicit and implicit tasks for assessing hedonic-versus nutrition-based attitudes towards food in French children. Appetite, 96, 580-587. https://doi.org/10.1016/j.appet.2015.10.026. 
Nicklaus, S. (2015). Sensory testing in new product development: working with children. In J. Delarue, J. B. Lawlor, \& M. Rogeaux (Eds.), Rapid sensory profiling techniques and related methods. Applications in new product development and consumer research (1st ed., pp. 473-484). Cambridge, UK: Woodhead Publishing.

Nicklaus, S. (2016a). Relationships between early flavor exposure, and food acceptability and neophobia. In P. Etiévant, E. Guichard, C. Salles, \& A. Voilley (Eds.), Flavor: From food to behaviors, Wellbeing and health (460 p.) (Vol. WPF 299, pp. 293-311). Cambridge, UK: Elsevier.

Nicklaus, S. (2016b). The role of food experiences during early childhood in food pleasure learning. Appetite, 104, 3-9. https://doi.org/10.1016/j.appet.2015.08.022.

Nicklaus, S., \& Monnery-Patris, S. (2018). Food neophobia in children and its relationships with parental feeding practices. In S. Reilly (Ed.), Food neophobia. behavioral and biological influences (Woodhead publishing series in food science, technology and nutrition 1ère ed., pp. 255-286). Elsevier.

Nicklaus, S., Boggio, V., Chabanet, C., \& Issanchou, S. (2004). A prospective study of food preferences in childhood. Food Quality and Preference, 15(7-8), 805-818.

Nicklaus, S., Boggio, V., Chabanet, C., \& Issanchou, S. (2005a). A prospective study of food variety seeking in childhood, adolescence and early adult life. Appetite, 44(3), 289-297.

Nicklaus, S., Boggio, V., \& Issanchou, S. (2005b). Food choices at lunch during the third year of life: High selection of animal and starchy foods but avoidance of vegetables. Acta Paediatrica, 94(7), 943-951.

Nicklaus, S., Chabanet, C., Boggio, V., \& Issanchou, S. (2005c). Food choices at lunch during the third year of life: Increase in energy intake but decrease in variety. Acta Paediatrica, 94(8), $1023-1029$.

Nicklaus, S., Demonteil, L., \& Tournier, C. (2015). Modifying the texture of foods for infants and young children. In J. Chen \& A. Rosenthal (Eds.), Modifying food texture. Volume 2: Sensory analysis, consumer requirements and preferences (Vol. 2, pp. 187-222). London: Woodhead.

Ogunlesi, T. A., Ayeni, V. A., Adekanmbi, A. F., \& Fetuga, B. M. (2014). Determinants of timely initiation of complementary feeding among children aged 6-24 months in Sagamu, Nigeria. Nigerian Journal of Clinical Practice, 17(6), 785-790. https://doi.org/10.4103/11193077.144399.

Oliveira, D. A., Castro, I. R., \& Jaime, P. C. (2014). Complementary feeding patterns in the first year of life in the city of Rio de Janeiro, Brazil: Time trends from 1998 to 2008. [Research support, non-U.S. Gov't]. Cadernos de Saúde Pública, 30(8), 1755-1764.

Pantoja-Mendoza, I. Y., Melendez, G., Guevara-Cruz, M., \& Serralde-Zuniga, A. E. (2014). Review of complementary feeding practices in Mexican children. Nutrición Hospitalaria, 31(2), 552-558. https://doi.org/10.3305/nh.2015.31.2.7668.

Reale, S., Hamilton, J., Akparibo, R., Hetherington, M. M., Cecil, J. E., \& Caton, S. J. (2019). The effect of food type on the portion size effect in children aged 2-12 years: A systematic review and meta-analysis. [Review]. Appetite, 137, 47-61. https://doi.org/10.1016/j.appet.2019. 01.025 .

Rebhan, B., Kohlhuber, M., Schwegler, U., Koletzko, B. V., \& Fromme, H. (2009). Infant feeding practices and associated factors through the first 9 months of life in Bavaria, Germany. [Article]. Journal of Pediatric Gastroenterology and Nutrition, 49(4), 467-473.

Remy, E., Issanchou, S., Chabanet, C., \& Nicklaus, S. (2013). Repeated exposure of infants at complementary feeding to a vegetable puree increases acceptance as effectively as flavor-flavor learning and more effectively than flavor-nutrient learning. Journal of Nutrition, 143(7), 1194-1200. https://doi.org/10.3945/jn.113.175646.

Remy, E., Divert, C., Rousselot, J., Brondel, L., Issanchou, S., \& Nicklaus, S. (2014). Impact of energy density on liking for sweet beverages and caloric-adjustment conditioning in children. The American Journal of Clinical Nutrition, 100(4), 1052-1058. https://doi.org/10.3945/ ajen.114.087452. 
Rioux, C. (in press). Food neophobia in childhood. In H. L. Meiselman (Ed.), Handbook of eating and drinking: Interdisciplinary perspectives. Springer.

Roberto, C. A., Baik, J., Harris, J. L., \& Brownell, K. D. (2010). Influence of licensed characters on children's taste and snack preferences. Pediatrics, 126(1), 88-93. https://doi.org/10.1542/ peds.2009-3433.

Roedder, J. D. (1999). Consumer socialization of children: A retrospective look at twenty-five years of research. Journal of Consumer Research, 26(3), 183-213.

Savage, J. S., Fisher, J. O., \& Birch, L. L. (2007). Parental influence on eating behavior: Conception to adolescence. The Journal of Law, Medicine \& Ethics, 35(1), 22-34. https://doi.org/10.1111/ j.1748-720X.2007.00111.x.

Schaal, B. (1988). Olfaction in infants and children: Developmental and functional perspectives. Chemical Senses, 13(2), 145-190.

Schaal, B. (2005). From amnion to colostrum to milk. Odour bridging in early developmental transitions. In B. Hopkins \& S. Johnson (Eds.), Prenatal development of postnatal functions. Advances in infancy research (Vol. 2, pp. 51-102). New York: Praeger.

Schaal, B. (2016). How amniotic fluid shapes early odor-guided responses to colostrum and milk (and more). In P. Etiévant, E. Guichard, C. Salles, \& A. Voilley (Eds.), Flavor: From food to behaviors, wellbeing and health (460 p.) (Vol. WPF 299, pp. 52-72). Cambridge, UK: Elsevier.

Schaal, B., Marlier, L., \& Soussignan, R. (2000). Human foetuses learn odours from their pregnant mother's diet. Chemical Senses, 25(6), 729-737.

Schwartz, C., Chabanet, C., Lange, C., Issanchou, S., \& Nicklaus, S. (2011). The role of taste in food acceptance at the beginning of complementary feeding. Physiology \& Behavior, 104, 646-652.

Schwartz, C., Chabanet, C., Laval, C., Issanchou, S., \& Nicklaus, S. (2013). Breastfeeding duration: Influence on taste acceptance over the first year of life. British Journal of Nutrition, 109(6), 1154-1161. https://doi.org/10.1017/S0007114512002668.

Schwartz, C., Chabanet, C., Szleper, E., Feyen, V., Issanchou, S., \& Nicklaus, S. (2017). Infant acceptance of primary tastes and fat emulsion: Developmental changes and links with maternal and infant characteristics. Chemical Senses, 42(7), 593-603. https://doi.org/10.1093/chemse/ bjx 040 .

Sharps, M., \& Robinson, E. (2015). Perceived eating norms and vegetable consumption in children. International Journal of Behavioral Nutrition and Physical Activity, 12, 135. https://doi.org/ 10.1186/s12966-015-0296-Z.

Shutts, K., Kinzler, K. D., \& DeJesus, J. M. (2013). Understanding infants' and children's social learning about foods: Previous research and new prospects. [Review]. Developmental Psychology, 49(3), 419-425. https://doi.org/10.1037/a0027551.

Siega-Riz, A. M., Deming, D. M., Reidy, K. C., Fox, M. K., Condon, E., \& Briefel, R. R. (2010). Food consumption patterns of infants and toddlers: Where are we now? Journal of the American Dietetic Association, 110(12), S38-S51. https://doi.org/10.1016/j.jada.2010.09.001.

Skinner, J. D., Carruth, B. R., Bounds, W., Ziegler, P., \& Reidy, K. (2002). Do food-related experiences in the first 2 years of life predict dietary variety in school-aged children? Journal of Nutrition Education and Behavior, 34(6), 310-315.

Sosa, M., \& Hough, G. (2006). Sensory expectations of children from different household incomes for a branded confectionary product. Journal of Sensory Studies, 21(2), 155-164.

Soussignan, R., Schaal, B., Marlier, L., \& Jiang, T. (1997). Facial and autonomic responses to biological and artificial olfactory stimuli in human neonates: Re-examining early hedonic discrimination of odors. Physiology \& Behavior, 62(4), 745-758.

Statistics Indonesia (Badan Pusat Statistik-BPS), National Population and Family Planning Board (BKKBN), Kementerian Kesehatan (Kemenkes-MOH), \& ICF International. (2013). Indonesia Demographic and Health Survey 2012 (p. 544). Jakarta: B. BPS, Kemenkes, and ICF International. 
Story, M., \& French, S. (2004). Food advertising and marketing directed at children and adolescents in the US. International Journal of Behavioral Nutrition and Physical Activity, 1(1), 3. https://doi.org/10.1186/1479-5868-1-3.

Sullivan, S. A., \& Birch, L. L. (1990). Pass the sugar, pass the salt: Experience dictates preference. Developmental Psychology, 26(4), 546-551.

Sullivan, S. A., \& Birch, L. L. (1994). Infant dietary experience and acceptance of solid foods. Pediatrics, 93(2), 271-277.

Sun, J., Dai, Y., Zhang, S., Huang, J., Yang, Z., Huo, J., \& Chen, C. (2011). Implementation of a programme to market a complementary food supplement (Ying Yang Bao) and impacts on anaemia and feeding practices in Shanxi, China. Matern Child Nutr, 7(Suppl 3), 96-111. https://doi.org/10.1111/j.1740-8709.2011.00353.x.

Tang, L., Lee, A. H., \& Binns, C. W. (2015). Predictors of early introduction of complementary feeding: Longitudinal study. Pediatrics International, 57(1), 126-130. https://doi.org/10.1111/ ped.12421.

Taylor, C. M., Wernimont, S. M., Northstone, K., \& Emmett, P. M. (2015). Picky/fussy eating in children: Review of definitions, assessment, prevalence and dietary intakes. Appetite, 95, 349-359. https://doi.org/10.1016/j.appet.2015.07.026.

Trabulsi, J. C., \& Mennella, J. A. (2012). Diet, sensitive periods in flavour learning, and growth. International Review of Psychiatry (Abingdon), 24(3), 219-230. https://doi.org/10.3109/ 09540261.2012.675573.

Turnbull, B., \& Matisoo-Smith, E. (2002). Taste sensitivity to 6-n-propylthiouracil predicts acceptance of bitter-tasting spinach in 3-6-y-old children. The American Journal of Clinical Nutrition, 76(5), 1101-1105.

Wagner, S., Issanchou, S., Chabanet, C., Marlier, L., Schaal, B., \& Monnery-Patris, S. (2013). Infants' hedonic responsiveness to food odours: A longitudinal study during and after weaning (8, 12 and 22 months). [research]. Flavour, 2, 19. https://doi.org/10.1186/2044-7248-2-19.

Wagner, S., Issanchou, S., Chabanet, C., Lange, C., Schaal, B., \& Monnery-Patris, S. (2019). Weanling infants prefer the odors of green vegetables, cheese, and fish when their mothers consumed these foods during pregnancy and/or lactation. Chemical Senses, 44(4), 257-265. https://doi.org/10.1093/chemse/bjz011.

Wardle, J., \& Huon, G. (2000). An experimental investigation of the influence of health information on children's taste preferences. Health Education and Research, 15(1), 39-44.

WHO World Health Organization. (2003). Global strategy for infant and young child feeding. Geneva: WHO.

Wiggins, S. (2019). Moments of pleasure: A preliminary classification of gustatory mmms and the enactment of enjoyment during infant mealtimes. Frontiers in Psychology, 10, 1404. https://doi.org/10.3389/fpsyg.2019.01404.

Yeomans, M. R. (2012). Flavour-nutrient learning in humans: An elusive phenomenon? Physiology \& Behavior, 106(3), 345-355. https://doi.org/10.1016/j.physbeh.2012.03.013.

Zandstra, E. H., \& de Graaf, C. (1998). Sensory perception and pleasantness of orange beverages from childhood to old age. Food Quality and Preference, 9(1/2), 5-12.

Zeinstra, G. G., Renes, R. J., Koelen, M. A., Kok, F. J., \& de Graaf, C. (2010). Offering choice and its effect on Dutch children's liking and consumption of vegetables: A randomized controlled trial. American Journal of Clinical Nutrition, 91(2), 349-356. https://doi.org/10.3945/ ajen.2009.28529.

Zhou, H., Wang, X. L., Ye, F., Zeng, X. L., \& Wang, Y. (2012). Relationship between child feeding practices and malnutrition in 7 remote and poor counties, P R China. Asia Pac J Clin Nutr, 21(2), 234-240. 